\title{
Major hepatic resections in infancy and childhood
}

\section{J. M. HOWAT}

From The Hospital for Sick Children, Great Ormond Street, London

SUMMARY Nineteen infants and children who had hepatic lobectomy or segmental resection of the liver for tumours are described. Fourteen had lobectomy for malignant tumours but only three survived for more than a year. Four of the five patients who had resections for hamartomas have survived for 18 months or more. The main problem encountered at operation was haemorrhage, which was responsible for the entire operative mortality of $31 \%$. A transient disturbance of liver function occurred after operation in both patients who had preoperative radiotherapy.

In infants and children hepatic lobectomy and segmental resection of the liver are undertaken almost exclusively for the removal of benign and malignant tumours of the liver. These are rare conditions, comprising $2.8 \%$ of the tumours at the Babies' Hospital, New York (Andersen, 1951), and $2.3 \%$ of the tumour material at the Hospital for Sick Children, Great Ormond Street (Claireaux and Williams, 1969). Edmonson (1956) observed that 'there are few sources of information regarding the general problem of liver tumours in infants and children and their surgical treatment, the literature Received for publication 4 November 1970. dealing mainly with case reports or at most with reviews of specific tumours'. This statement is still true, although in recent years improvements in surgical technique, anaesthesia, and postoperative care have led to a more aggressive approach to these tumours by planned resections based on accurate delineation of the internal segmental divisions of the liver according to its blood supply and biliary drainage.

This paper describes the anatomical basis of these resections and the clinical findings, management, and results of treatment in 19 infants and children who had hepatic lobectomies or segmental

\section{RIGHT LOBE}

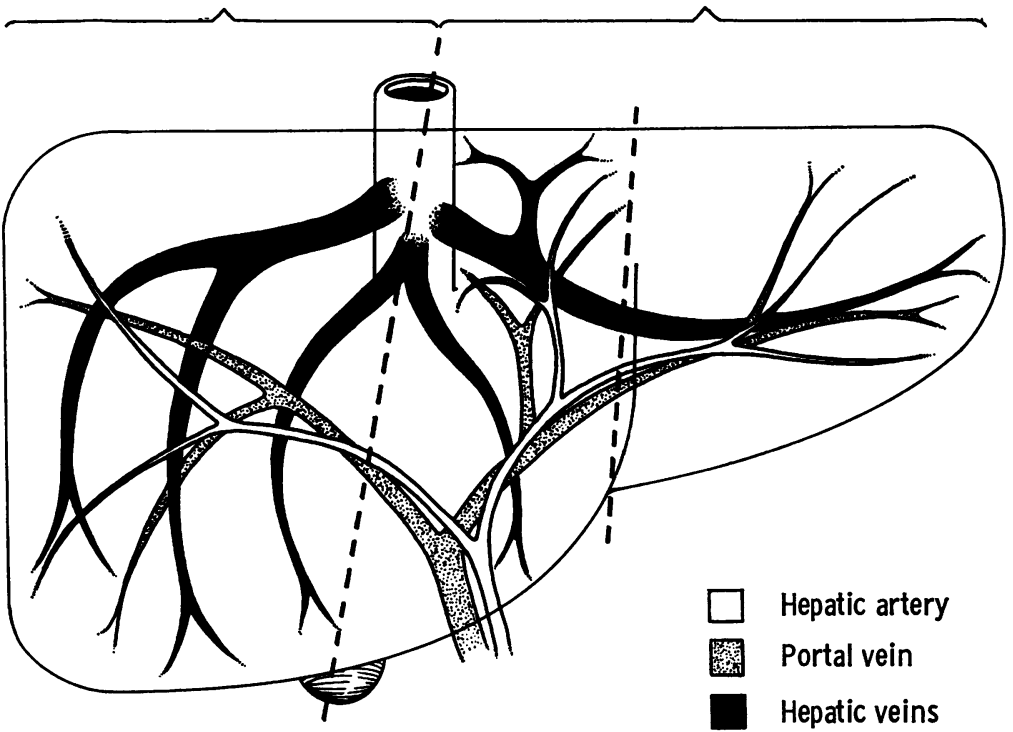

Fig. 1. Hepatic anatomy. 
resections of the liver for tumour at the Hospital for Sick Children, Great Ormond Street, in the years 1954 to 1969 inclusive, and discusses their role in the treatment of liver tumours. Tumours treated by local excision are not included.

\section{Anatomy (Fig. 1)}

The following account is based on the description of Wilson and Wolf (1966), in which the liver is divided into right and left lobes according to its afferent blood supply by a lobar fissure extending along a line from the gallbladder to the inferior vena cava; the left lobe is subdivided into medial and lateral segments along the attachment of the falciform ligament. The right and left lobes correspond to the right and left halves and the lateral segment of the left lobe to the entire left lobe under the alternative nomenclature of Hobsley (1958). Each left lobar segment is further divided into

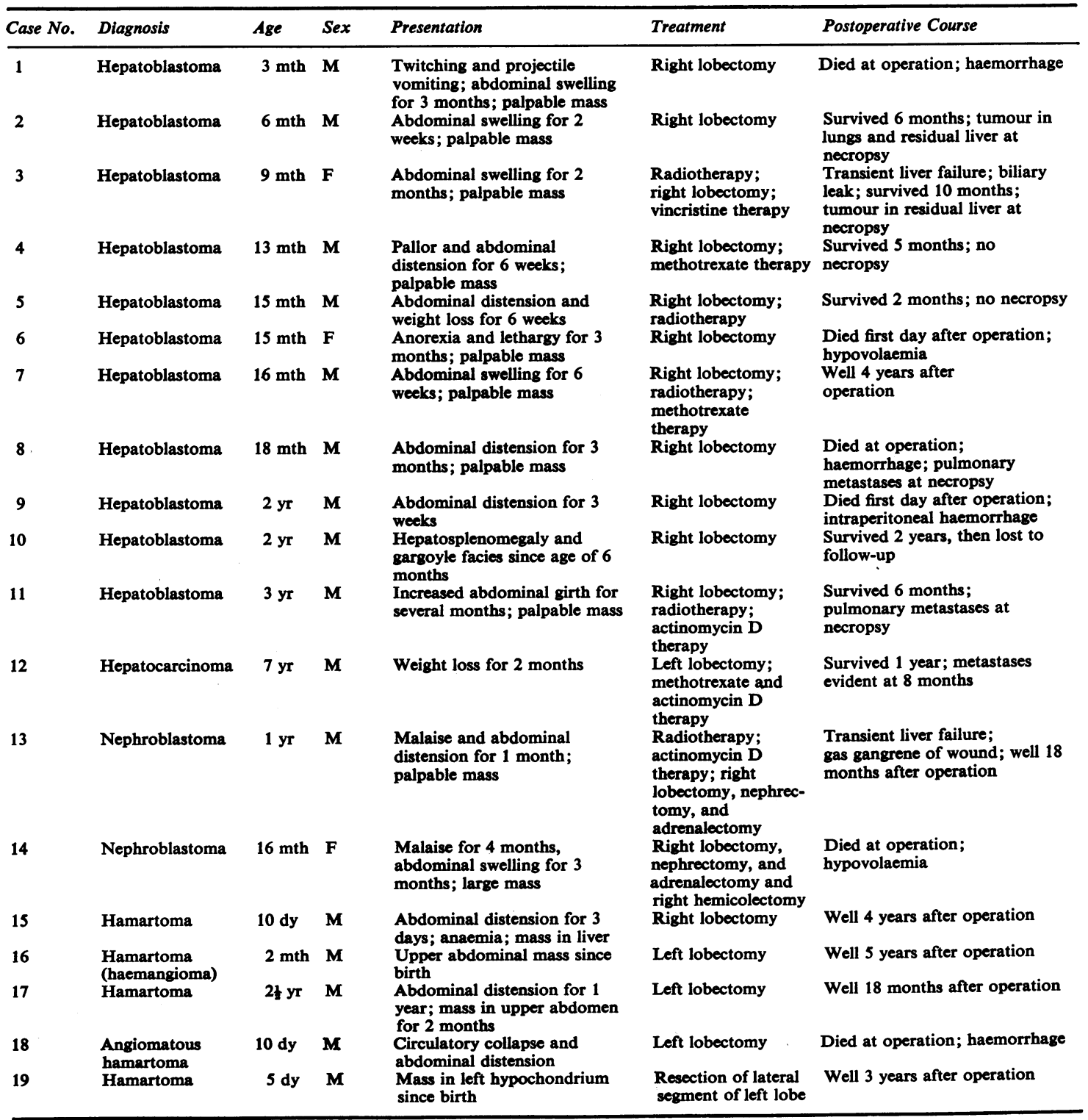

Table I Clinical material 
superior and inferior areas and the right lobe into anterior and posterior segments, each with its own afferent blood vessels with no intrahepatic collateral circulation between them. Unfortunately the three main hepatic veins do not have this segmental distribution but lie in intersegmental planes at right angles to the afferent vascular structures. This overlap limits the application of segmental resection, which, with the exception of the lateral segment of the left lobe, is liable to cause obstruction to the venous drainage and infarction of unresected segments. The entry of the hepatic veins into the inferior vena cava may be separate or the left may form a common channel with the middle or right vein; there are also variable but important small short branches entering the vena cava.

\section{Clinical Features (Table 1)}

The age of the 19 patients ranged from 5 days to 7 years. Three patients $(16 \%)$, all with hamartomas, presented in the neonatal period, six $(37 \%)$ in the first year of life, seven $(42 \%)$ in the second year, three $(16 \%)$ in the third year, and only one patient was over 3 years of age. Males predominated in the series by 16 to 3 ; all the patients with hamartomas were male.

The duration of symptoms and signs varied from one day to 21 months; only two patients had symptoms for more than 3 months. The outstanding signs were abdominal distension and a palpable, usually nodular mass in the upper abdomen (14 patients). Anaemia was the next most common feature (10 patients). Jaundice was noted in only one infant. None of the patients had any gross

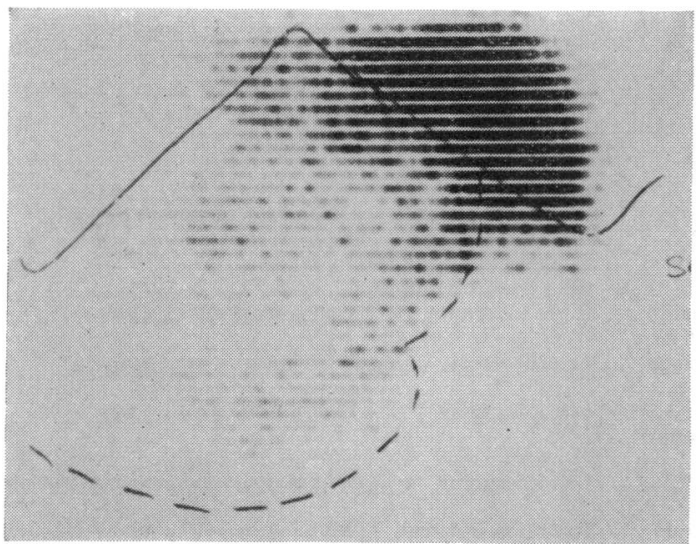

Fig. 2. Liver scan showing large mass in right lobe of liver. disturbance of liver function, but in 10 there was an increased plasma $\gamma$ globulin concentration.

Pulmonary metastases were excluded in all patients by radiological examination of the chest. A plain $x$-ray film of the abdomen confirmed the presence of an upper abdominal mass in 14 patients. Eleven patients had an IVP, which was normal in seven, showed the typical features of nephroblastoma in two, and in two others-subsequently found at laparotomy to have hamartomasshowed downward displacement of the kidney by a mass above it. One patient had a liver scan which showed a large space-occupying lesion in the right lobe of the liver (Fig. 2).

\section{Pathology}

Thirteen tumours involved the right lobe of the liver and six the left lobe; $86 \%$ of the malignant tumours involved the right lobe and $80 \%$ of the benign lesions were in the left lobe.

Eleven of the neoplasms were hepatoblastomas which usually formed a single mass confined to one

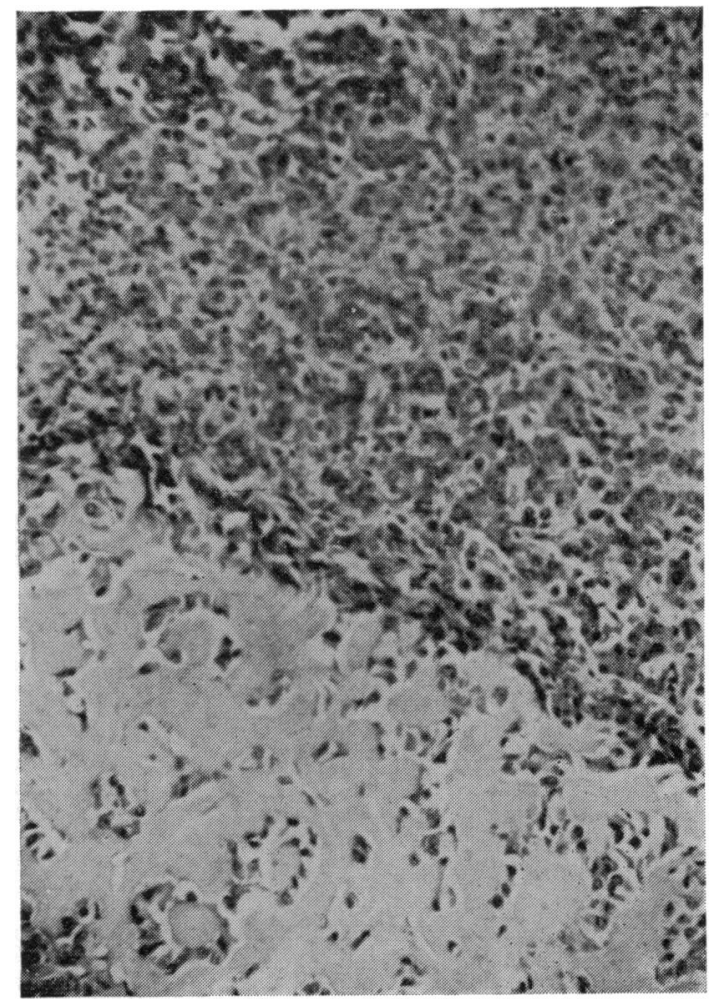

Fig. 3. Hepatoblastoma showing osteoid formation ( $H \& E, \times 400)$. 


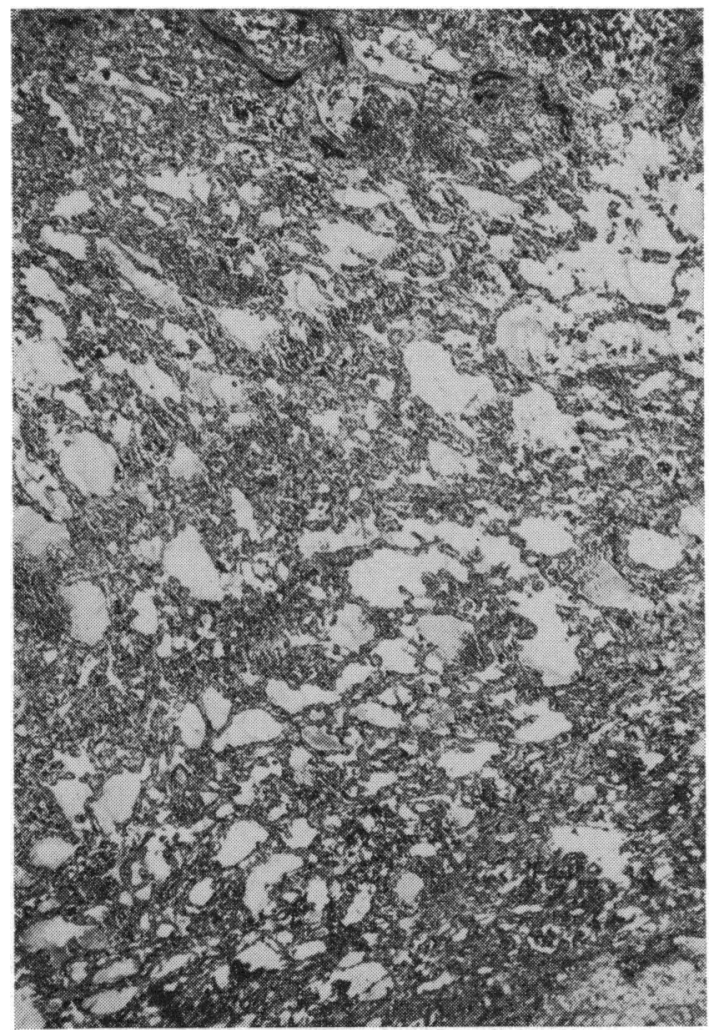

Fig. 4. Angiomatous hamartoma $(H \& E, \times 200)$.

lobe of the liver and had a nodular appearance; these tumours consisted mainly of closely packed cells resembling foetal liver, with high mitotic activity and no cellular differentiation; squamous metaplasia and osteoid formation were also seen (Fig. 3). In two patients a nephroblastoma of the right kidney involved the liver by direct invasion. A 7-year-old boy had a hepatocarcinoma histologically identical to an adult primary carcinoma of the liver but without cirrhosis.

The five benign lesions were hamartomas whose gross appearance was similar to the hepatoblastomas but they were well circumscribed and encapsulated. They consisted mainly of pale connective tissue with areas of cystic degeneration; two of them were largely composed of engorged angiomatous tissue (Fig. 4).

\section{Management}

Before operation anaemia was corrected if necessary. In two patients (cases 3 and 13) the tumour was initially considered inoperable but after radiotherapy was resected four and two months later respectively. Immediate hepatic resection was performed in the remaining 17 cases.

The extent of the resections and the lesions for which they were performed are shown in Table II. Resections of the left lobe were performed through a transverse upper abdominal incision; right lobectomies required a thoraco-abdominal approach but the operability of the tumour was first assessed from within the abdomen. After division of the falciform ligament and the ligamentum teres, the peritoneal attachments of the liver to the diaphragm were divided. With the exception of the patient who had a resection of the lateral segment of the left lobe, in whom control of bleeding was achieved by digital compression of the portal vein and hepatic artery in the right free border of the lesser omentum, the afferent blood supply and biliary drainage of the lobe to be resected were secured in the porta hepatis.

\begin{tabular}{|c|c|c|c|}
\hline \multirow[t]{2}{*}{ Lesion } & \multicolumn{3}{|l|}{ Resection } \\
\hline & Right Lobe & Left Lobe & $\begin{array}{l}\text { Lateral } \\
\text { Segment of } \\
\text { Left Lobe }\end{array}$ \\
\hline $\begin{array}{l}\text { Hepatoblastoma } \\
\text { Hepatocarcinoma }\end{array}$ & 10 & $\begin{array}{l}1 \\
1 \\
\text { (+ partial } \\
\text { right) }\end{array}$ & \\
\hline $\begin{array}{l}\text { Secondary nephroblastoma } \\
\text { Hamartoma }\end{array}$ & $\begin{array}{l}2 \\
1\end{array}$ & 20.8. & 1 \\
\hline Total & 13 & 5 & 1 \\
\hline
\end{tabular}

Table II Lesions and extent of resections

In five of the right lobectomies slings were passed round the inferior vena cava above and below the point of entry of the hepatic veins which were then secured before division of liver tissue but in the others the hepatic veins were divided in their intrahepatic location. Division of liver tissue in all cases was by diathermy and the larger tributaries of the hepatic veins were under-run with a suture. Both patients with nephroblastomas had, in addition to a right hepatic lobectomy, a right nephrectomy and adrenalectomy, and one also had a right hemicolectomy. Drainage of the common bile duct was necessary in only one patient who, nevertheless, required subsequent drainage of a biliary leak. Blood loss at operation ranged from $350 \mathrm{ml}$ to $11,000 \mathrm{ml}$, with an average loss of $700 \mathrm{ml}$.

In the period immediately after operation no special treatment was given other than to ensure an adequate peripheral circulation. One patient had radiotherapy after operation, three were given cytoxic drugs (methotrexate, vincristine, or actinomycin D), and two had both forms of treatment. 
After operation two patients had disturbed liver function. Other postoperative complications were a fatal haemorrhage, gas gangrene of the wound, an intestinal obstruction, and a biliary leak. Only two patients had any notable disturbance of liver function, and in both it was transient. In the 24 hours immediately following operation both became comatose and had convulsions. One developed rapidly increasing jaundice requiring exchange transfusion, but after a stormy convalescence recovered completely. The other became hypoglycaemic and developed a right hemiparesis, and although not jaundiced had a high plasma ammonium; he also recovered. These were the only two patients who had preoperative radiotherapy.

\section{Results}

There were six deaths in the series directly attributable to operation, a mortality of $31 \%$. Four deaths occurred at operation, three from uncontrollable haemorrhage (two from the inferior vena cava and one from the liver) and one from hypovolaemia. In the immediate postoperative period one patient died from hypovolaemia and one from bleeding.

Only three patients with malignant tumours survived for more than a year; one patient with hepatoblastoma was lost to follow-up by emigration having survived for two years, one is alive at four years, and one patient with nephroblastoma is alive 18 months after operation. Apart from one operative death in an infant presenting with intraperitoneal haemorrhage the patients with hamartomas are alive and well from 18 months to five years after operation.

\section{Discussion}

The liver tumours of childhood have been divided by Keeling (1971) into four categories, hamartomas (including haemangiomas) and three groups of neoplasms: hepatoblastomas occurring in infants and containing epithelial and mesenchymal elements; hepatocellular carcinomas, purely epithelial tumours of older children; and rhabdomyoblastic tumours also occurring in older children. This classification has been used in the present series which also includes two cases of secondary invasion of the liver by nephroblastoma.

The classical primary liver neoplasm of childhood is the hepatoblastoma; hepatocellular carcinoma is very rare and unlike adult carcinoma, which is much commoner in cirrhotic than in normal livers, is not associated with cirrhosis. Hepatoblastomas mostly occur under the age of 2 years and affect males much more commonly than females. They are embryonal tumours developing during organogenesis from immature liver tissue (Willis, 1960) and the mixed variety is analogous to nephroblastoma. The tumour usually forms a single mass confined to one lobe of the liver-predominantly the right-and although the tumour is highly malignant spreading by the bloodstream, metastases generally occur late in the course of the disease (Edmonson, 1956). Early radical surgery is therefore the logical treatment and several long-term survivors have been reported (Debré, Mozziconacci, Habib, and Habib, 1954; Borman, Harbott, and Morris, 1961 ; Fish and McCary, 1966). The average duration of life without treatment is four to six months from the onset of 'symptoms (Bodian and White, 1952; Bigelow and Wright, 1953). Ishak and Glunz (1967) found radiotherapy and cytotoxic therapy alone and after surgery to be of little or no value, but Lascari (1970) has reported complete regression of a hepatoblastoma treated with vincristine alone. The longest survivors in this series had both forms of treatment.

Primary neoplasms of the liver may be mimicked by secondary spread of tumour from other sites, most commonly neuroblastoma closely followed by nephroblastoma (Minor, 1969). The indications for removal of metastatic lesions are not so clear as those for primary liver tumours because of the possibility of concomitant and yet occult metastases in other organs. Nevertheless, hepatic resection is an appropriate form of treatment for a single liver secondary if the primary can also be removed and there are no other evident metastases. The prognosis following resection is more favourable when the liver has been involved by direct invasion than if metastases are blood-borne (Wilson and Wolf, 1966). The success of radical surgery in one of the nephroblastomas in this series supports the above contention; he is well 18 months later and the great majority of recurrences of nephroblastoma occur within a year (Williams, 1968).

Hamartomas are tumour-like, non-neoplastic malformations containing a mixture of tissues indigenous to the part affected with an excess of one or more of them (Willis, 1962) and are named according to the predominant tissue present, eg, mesenchymal hamartoma, angiomatous hamartoma. They usually become manifest under the age of 20 months (Edmonson, 1956), and unlike the findings in this series, affect both sexes and both lobes of the liver equally. Like primary neoplasms, an abdominal swelling and a palpable mass in the upper abdomen are usually the first signs; differentiation from neoplasms depends on laparotomy and biopsy. Hamartomas, though histologically benign, should be excised because of difficulties caused by 
their size. Mesenchymomas in nearly every case lie at the lower margin of the liver (Edmonson, 1956) and can be removed by local excision. Angiomatous hamartomas and haemangiomas may require urgent operative treatment because of bleeding, and the latter also because of high output cardiac failure or thrombocytopenic purpura resulting from trapping of platelets (Minor, 1969).

Assessment of children with a mass in the liver should include liver function tests, though they are usually normal, a plain radiograph of the abdomen and an IVP to determine whether the mass is due to a nephroblastoma or neuroblastoma, although, as in two cases in this series, a large liver mass can cause confusion by displacing the kidney. A liver scan, besides showing the extent of the spaceoccupying lesion, may indicate whether preoperative radiotherapy has reduced its size. Ong and Leong (1969) have found splenoportovenography, hepatic arteriography and inferior vena cavography helpful in the preoperative assessment of adults with carcinoma of the liver, but a precise assessment of the nature and operability of a liver tumour can be made only at laparotomy (Borman et al, 1961).

Access and haemorrhage are the problems confronting the surgeon undertaking the removal of hepatic tumours and cysts (Grime, Moore, Nicholson, and Whitehead, 1959). Haemorrhage was the main problem in this series and was responsible for the entire operative mortality. The afferent blood supply can be readily and safely controlled, but, since the entry of the hepatic veins into the inferior vena cava is variable, it may be preferable to divide them in their intrahepatic course (Wilson and Wolf, 1966). This may cause considerable haemorrhage which can be controlled by placing slings round the inferior vena cava above and below the point of entry of the hepatic veins before division of the liver parenchyma as advocated by Nixon (1965); these slings are invaluable if the inferior vena cava or the hepatic veins are damaged.

A remnant of hepatic parenchyma of as little as $10 \%$ of the original total is sufficient to maintain life and reasonable metabolic activity without artificial support within seven to 10 days of hepatic resection (McDermott, Greenberger, Isselbacher, and Weber, 1963). In children sufficient liver tissue should remain following the standard hepatic resections to preserve normal function, but early postoperative radiotherapy and/or chemotherapy may impair liver regeneration and produce severe long-term hepatic impairment Filler, Tefft, Vawter, Maddock, and Mitus, 1969). Experi- ence in this series suggests that disturbances of liver function may occur when the patient has had radiotherapy before operation.

I am indebted to Mr H. H. Nixon, Mr D. J. Waterston, and Professor A. W. Wilkinson for permission to report these cases and for guidance in the preparation of this paper, and to the Department of Medical Illustration, Institute of Child Health, for producing the illustrations.

\section{References}

Andersen, D.H.(1951). Tumours of infancy and childhood. I. A survey of those seen in the pathology laboratory of the Babies' Hospital during the years 1935 to 1950. Cancer (Philad.), 4, 890-906.

Bigelow, N. H., and Wright, A. W. (1953). Primary carcinoma of the liver in infancy and childhood. Cancer (Philad.), 6, 170178.

Bodian, M., and White, L. L. R. (1952). Neoplastic diseases in childhood. Gt Ormond Str. J., 4, 105-117.

Borman, J. B., Harbott, A. J., and Morris, D. (1961). Hepatic lobectomy in infancy for hepatoblastoma. Brit. J. Surg., 49, 11-13.

Claireaux, A. E., and Williams, D. I. (1969). In Recent Advances in Surgery, 7th ed., edited by Selwyn Taylor. p. 50. Churchill, London.

Debré, R., Mozziconacci, P., Habib, R., and Habib, E. (1954). L'hépatoblastome (tumeur maligne due foie à cellules embryonnaires). Arch. franc. Pédiat., 11, 1013-1034.

Edmonson, H. A. (1956). Differential diagnosis of tumors and tumorlike lesions of liver in infancy and childhood. Amer. J. Dis. Child., 91, 168-186.

Filler, R. M., Tefft, M., Vawter, G. F., Maddock, C., and Mitus, A. (1969). Hepatic lobectomy in childhood: effects of X-ray and chemotherapy. J. pediat. Surg., 4, 31-41.

Fish, J. C., and McCary, R. G. (1966). Primary cancer of the liver in childhood. Arch. Surg., 93, 355-359.

Grime, R. T., Moore, T., Nicholson, A., and Whitehead, R. (1959). Cystic hamartomas and polycystic disease of the liver. Brit. J. Surg., 47, 307-313.

Hobsley, M. (1958). Intrahepatic anatomy. A surgical evaluation. Brit. J. Surg., 45, 635-644.

Ishak, K. G., and Glunz, P. R. (1967). Hepatoblastoma and hepatocarcinoma in infancy and childhood. Report of 47 cases. Cancer (Philad.), 20, 396-422.

Keeling, J. W. (1971). Liver tumours in infancy and childhood. Arch. Path., in press.

Lascari, A. D. (1970). Vincristine therapy in an infant with probable hepatoblastoma. Pediatrics, 45, 109-112.

McDermott, W. V. Jr., Greenberger, N. J., Isselbacher, K. J., and Weber, A. L. (1963). Major hepatic resections: diagnostic techniques and metabolic problems. Surgery, 54, 56-66.

Minor, C. L. (1969). In Pediatric Surgery, 2nd ed., edited by W. T. Mustard, M. M. Ravitch, W. H. Snyder, Jr., K. J. Welch, and C. D. Benson, p. 741. Year Book Inc., Chicago.

Nixon, H. H. (1965). Hepatic tumours in childhood. and their treatment by major hepatic resection Arch. Dis. Childh., 40, 169-172.

Ong, C. B., and Leong, C. H. (1969). Surgical treatment of primary liver cancer. J. roy. Coll. Surg. Edinb., 14, 42-55.

Williams, D. I. (1968). Nephroblastoma: radiology and diagnosis. In Paediatric Urology, edited by D. I. Williams, p. 402 . Butterworths, London.

Willis, R. A. (1960). The Pathology of Tumours, 3rd ed., p. 929. Butterworths, London.

Willis, R. A. (1962). In The Borderland of Embryology and Pathology, 2nd ed., p. 351. Butterworths, London.

Wilson, H., and Wolf, R. Y. (1966). Hepatic lobectomy: indications, technique and results. Surgery, 59, 472-482. 